theoretical conceptualisation of mental disorder. I doubt this, but in any case the main implication is that diagnosis of genuine depressive pathology would have to establish whether the individual with symptoms was reacting to a loss in a proportionate way and for about the right length of time. This, as Robert L. Spitzer notes in his foreword, would present serious challenges to the reliability of diagnosis.

However, there are other problems with the authors' approach. The DSM's conceptualisation of mental disorder assigns primary importance to distress, disability or risk thereof; these in turn are connected, of course, to perceived need to treat (or to wait watching). In this context of (unmanageable) distress, downturn in functioning or risk, it is questionable whether the normality of mood - in the sense of understandable in relation to context - plays a critical role. We may well be able to understand, somewhat or well enough, why a single parent with little social support and a history of significant losses should become depressed, with distress and disability. Why should they, nevertheless, not be offered treatment? So far as I can see, clinicians have little use for the distinction between normal and abnormal depression except in the sense that normal may be used to mean: self-limiting, unlikely to carry risk, and no need to treat. Contextualising is less the issue: harm, risk and need to treat are.

The issue identified by the authors - increase of pathologising and prescribing - is serious and current; and they make clear one key possible diagnosis, that the limits of pathology are being illegitimately stretched. The authors are expert in this position and their book is essential reading for anyone concerned with these problems. This remains so even if there are differentials, for example that methods of detection have improved, and/or that there is no lower limit on the extent of distress and disability that we will take to the clinic in hope of help, especially if encouraged, for instance by direct-to-consumer advertising.

Derek Bolton Institute of Psychiatry, Box P077, De Crespigny Park, London SE5 8AF, UK. Email: derek.bolton@iop.kcl.ac.uk

doi: 10.1192/bjp.bp.108.052720

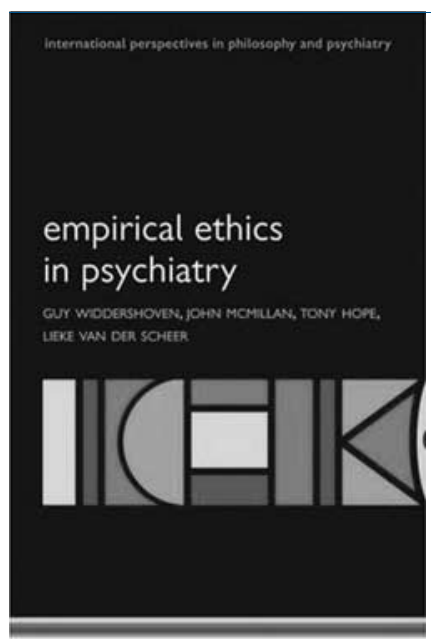

\section{Empirical Ethics in Psychiatry}

Edited by Guy Widdershoven, John McMillan, Tony Hope \& Lieke van der Scheer. Oxford University Press. 2008. f29.95 (pb). 264pp. ISBN: 9780199297368

'Empirical bioethics' aims to combine philosophical analysis with empirical data to produce ethical analyses that are sensitive to and informed by practice, practitioners and patients. There is, however, disagreement about how this can be achieved. Empirical Ethics explores this tension in psychiatry. Section one describes a range of practical and theoretical approaches (what empirical ethics is, the problem of the is/ought dichotomy and the naturalistic fallacy) and offers some reflections on possible methodologies, explanations and justifications for the emergence of empirical (bio)ethics as a discernable subfield of medical ethics. The second, longer section is devoted to specific examples of empirical ethics in practice that focus on ethical problems in psychiatry and mental health.

This book is both a comprehensive introduction to empirical bioethics and an exploration of familiar problems in psychiatric ethics. However, despite the common goal shared by all contributors, there is a wide variety of views on how the ethical and the empirical should be combined. Widdershoven and van der Scheer, for example, describe a pragmatic hermeneutic approach in which the practitioner, by virtue of his or her experience, is considered to have special moral knowledge that the empirical ethics researcher can access. In contrast, Verkerk, Polstra and de Jonge use case studies and Gidden's sociological theory of structuration to shed light on how healthcare structures influence our normative understandings of pressure and coercion. The editors have not shied away from including examples from both ends of the empirical ethics spectrum and many shades of grey in between. The excellent introduction and brilliantly clear first chapter by Hope and Macmillan gives even the novice reader the conceptual tools to begin to critically examine the chapters that follow.

This thoughtful and varied collection should appeal to practitioners primarily interested in psychiatric ethics, as well as those who are interested in the theory and practice of empirical ethics. Having just been tasked with developing a course on empirical bioethics, it comes as a great relief to find a book to which I can refer students; one that captures so well the possibilities, and problems, of the empirical ethics endeavour.

Jonathan Ives Lecturer in Behaviour Sciences, Centre for Biomedical Ethics, Primary Care Clinical Sciences, Primary Care Clinical Sciences Building, University of Birmingham, Edgbaston, Birmingham B15 2TT, UK. Email: j.c.ives@bham.ac.uk

doi: 10.1192/bjp.bp.108.053421

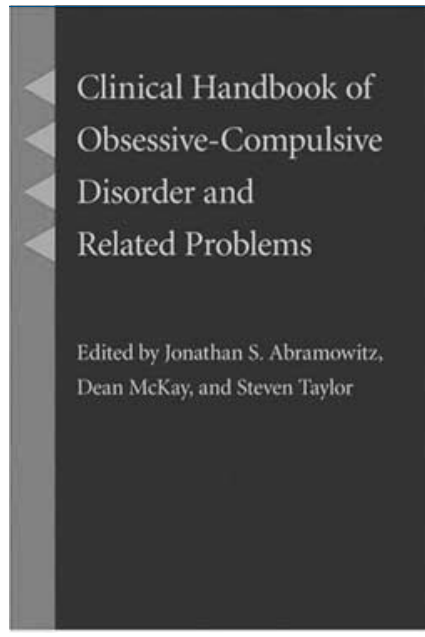

\section{Clinical Handbook of Obsessive-Compulsive Disorder and Related Problems}

Edited by Jonathan S. Abramowitz, Dean McKay \& Steven Taylor. The Johns Hopkins University Press. 2008. US\$60.00 (hb). 304pp. ISBN: 9780801886973

This book sets out to give a detailed account of the subtypes of obsessive-compulsive disorder and to consider whether there exists a spectrum of such disorders. The subtypes presented in Part I include those that will be familiar to most, such as fears of contamination, checking and unacceptable obsessive thoughts, and others like scrupulosity that may be less known. Each chapter 